Original scientific paper

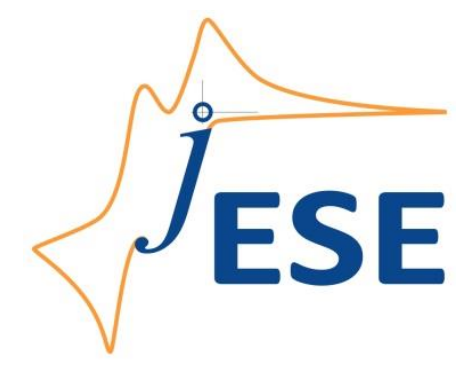

Open Access : : ISSN 1847-9286

www.jESE-online.org

\title{
Anticorrosive behaviour of lumefantrine hydrophobic layer on mild steel surface
}

\author{
Pavithra M. Krishnegowda, Venkatesha T. Venkatarangaiah $\bowtie$, \\ Punith Kumar M. Krishnegowda*, Anantha N. Subba Rao, Shubha H. Nataraj \\ Department of Chemistry, Kuvempu University, Shankaraghatta-577451, Shimoga, Karnataka, \\ India \\ *Department of Materials Engineering, Indian Institute of Science, Bangalore-560012, Karnataka, \\ India
}

${ }^{\circledR}$ Corresponding Author: drtvvenkatesha@yahoo.co.uk; Tel.: +91-9448855079

Received: March 22, 2016; Revised: May 17, 2016; Accepted: May 18, 2016

\begin{abstract}
The surface modification of mild steel was achieved by chemical treatment in lumefantrine (LF) solution. The surface morphology and wettability of modified surface was analysed by 3D profilometer and contact angle goniometer. The corrosion inhibition performance of modified mild steel surface in $1.0 \mathrm{M} \mathrm{HCl}$ solution was investigated by potentiodynamic polarization and electrochemical impedance techniques.Electrochemical measurements illustrate that the corrosion of mild steel in acidic chloride medium get substantially reduced by introducing LF film on its surface (94\% efficiency). Quantum chemical parameters were evaluated by ab initio method and they confer appropriate theoretical support to the experimental findings.
\end{abstract}

\section{Keywords}

Acid solutions; Mild steel; Polarization; Electrochemical impedance spectroscopy ;Acid corrosion

\section{Introduction}

The service life of metals can be improved by their surface modification using electroactive compounds [1]. Organic molecules containing $\mathrm{O}, \mathrm{N}, \mathrm{S}$ and polar functional groups are the extensively used electro active compounds, owing to their strong adsorption tendency on the metal surface. These electro active compounds form a thin film or molecular layers on the metal surface. Traditionally, hetero aromatic compounds have been used for mild steel (MS) protection [2-7]. However, these compounds are harmful to the environment due to their toxicity. Therefore, it 
becomes important to search for new, nontoxic and effective organic compounds to serve the same purpose. In this regard, drugs are the promising alternatives, referred as green corrosion inhibitors [8,9]. Drug molecules have been used for the corrosion inhibition of MS in different corrosive media and remarkable results have been reported [10-14]. In the present work, the antimalarial drug 'Lumefantrine' has been selected to protect the MS from corrosion in acidic chloride medium. The MS was chemically treated with $\mathrm{CHCl}_{3}$ solution containing lumefantrine (LF) and the corrosion behaviour of modified mild steel (MMS) surface was examined by electrochemical techniques.

\section{Experimental}

\section{Materials and sample preparation}

The experiments were performed with MS specimens having composition $0.04 \% \mathrm{C}, 0.35 \% \mathrm{Mn}$, $0.022 \% \mathrm{P}, 0.036 \% \mathrm{~S}$, and the remainder being Fe. The MS coupons of $1 \mathrm{~cm}^{2}$ area (exposed) with a $5 \mathrm{~cm}$ long stem isolated with araldite resin were used for electrochemical measurements. Prior to each experiment, the metal samples were abraded with series of emery papers (grade No. 220, 660 and 1200) followed by thorough wash using millipore water, acetone and then dried in hot air.

The aggressive solution of $1.0 \mathrm{M} \mathrm{HCl}$ was prepared from $\mathrm{AR}$ grade $37 \% \mathrm{HCl}$ and millipore water. The millipore water was obtained from Elix 3 Milli-pore system (Resistivity greater than $18 \mathrm{M} \Omega \mathrm{cm}$ at $25^{\circ} \mathrm{C}$ ). Lumefantrine was obtained from Ramdev Chemicals India Pvt. Ltd., Mumbai and its structure is as shown in Figure 1. The different concentrations of $\mathrm{CHCl}_{3}$ solutions of $\mathrm{LF}$ were prepared by dissolving desired amount of $\mathrm{LF}$ in $\mathrm{CHCl}_{3}$. The $\mathrm{MS}$ coupons were dipped in $100 \mathrm{ml}$ of $\mathrm{CHCl}_{3}$ solutions of LF for about $1 \mathrm{hr}$ to obtain MMS. After surface modification, the metal samples were dried and stored in desiccator for further corrosion studies. The MS coupon modified in $3 \mathrm{mM}$ LF solution was used for surface analyses.

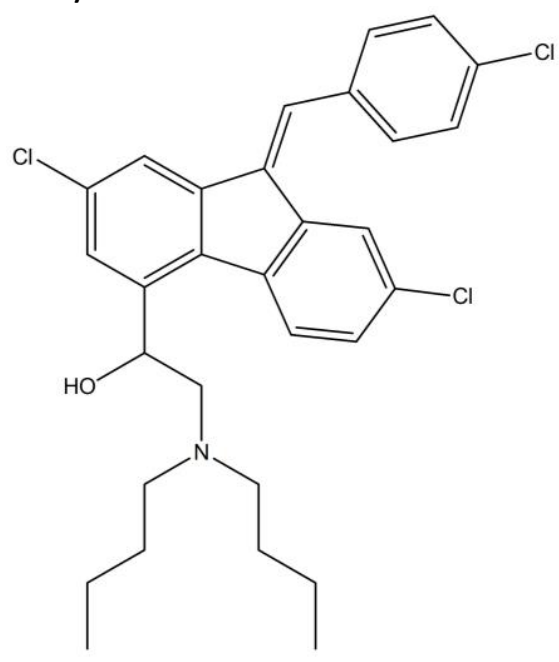

Figure 1. Structure of lumefantrine

\section{Contact angle measurement}

An OCA 30 from DataPhysics Instruments $\mathrm{GmbH}$, Germany was used to measure the contact angles. The contact angle of water on the metal sample was measured by the sessile drop method. A commercial goniometer was used with the volumes of water droplets fixed at $2 \mu \mathrm{L}$ and the measurements were performed at room temperature.Images of the Air/Liquid/Solid (A/L/S) systems were captured and processed using the 32-bit SCA 20 software. 


\section{Infrared spectra}

An infrared reflection absorption spectroscopy (GX spectrometer, Perkin Elmer, U.S.A.) instrument outfitted with a liquid nitrogen cooled mercury cadmium telluride (MCT) detector was used to take IR spectra. Before starting the experiments the sample and detector chambers were purged with nitrogen gas. The reported IR spectra were obtained with reference to bare steel substrate over 1024 optimized scans at $4 \mathrm{~cm}^{-1}$ resolution by using polarized beam spectra of modified surface.

The surface morphology

The surface of MS samples was examined by Zeta-20 True Color 3D Optical Profiler (Zeta Instruments, CA, U.S.A.). After the experiment, the metal samples were kept in a vacuum desiccator and were mounted on sample holder under the objective of the Optical Profiler, and the $2 \mathrm{D}$ photos were taken from the $50 \times$ magnified surface.

\section{Quantum chemical studies}

Quantum chemical calculations were performed using standard HyperChem, Release 8.0 software (Hypercube, Inc. GmBH Austria, USA). Geometrical structure of LF molecule was optimized by parametric (PM3) method. The optimized structure which has minimum energy value was used as the input structure for the geometrical optimization using ab initio method (HartreeFock method, 6-31G** basis set). The Polak-Rieberre algorithm which is fast and accurate was used for computation. The energy parameters in the form of root mean square gradient were kept at $0.1 \mathrm{kcal} / \AA ̊ \mathrm{~mol}$. $0.1 \mathrm{kcal} / \AA ̊ \AA \mathrm{mol}$.

\section{Electrochemical measurements}

Electrochemical measurements were conducted in a conventional glass cell using $\mathrm{CHI} 660 \mathrm{C}$ electrochemical analyzer ( $\mathrm{CH}$ Instruments, Austin, TX, USA). MS specimen $\left(1 \mathrm{~cm}^{2}\right)$, a platinum electrode and $\mathrm{Ag} / \mathrm{AgCl}$ electrode were used as working, auxiliary, and reference electrodes respectively. Prior to each electrochemical measurement, a stabilization period of 30 min was allowed to establish a steady state open circuit potential (OCP). Each experiment was carried out in triplicate and the average values of corrosion parameters are reported.

The potentiodynamic polarization (PDP) measurements were carried out over a potential range of $-200 \mathrm{mV}$ to $+200 \mathrm{mV}$ at OCP with a scan rate of $0.5 \mathrm{mV} \mathrm{s}^{-1}$. The corrosion kinetic parameters such as corrosion potential $\left(E_{\text {corr }}\right)$, corrosion current density $\left(I_{\text {corr }}\right)$, and anodic $\left(\beta_{\mathrm{a}}\right)$, and cathodic $\left(\beta_{\mathrm{c}}\right)$ Tafel slopes were evaluated by the software installed in the instrument.

The percentage inhibition efficiency $\eta_{\mathrm{T}} / \%$ was computed from $I_{\text {corr }}$ values using the following expression;

$$
\eta_{\mathrm{T}} / \%=\frac{I_{\text {corr }}^{\circ}-I_{\text {corr }}}{I_{\text {corr }}^{\circ}} \times 100
$$

where $I^{\circ}$ corrand $I_{\text {corr }}$ are the corrosion current densities without and with inhibitor, respectively.

The electrochemical impedance spectroscopy (EIS) measurements were carried at OCP in the frequency range $1 \mathrm{mHz}$ to $100 \mathrm{kHz}$ with $5 \mathrm{mV}$ sine wave as the excitation signal. Impedance data were analyzed using ZSimp-Win 3.21 software.

The inhibition efficiency $\eta_{\mathrm{Z}} / \%$ was evaluated from charge transfer resistance $\left(R_{\mathrm{ct}}\right)$ values using the following equation 


$$
\eta_{\mathrm{z}} / \%=\frac{R_{\mathrm{ct}}-R_{\mathrm{ct}}^{\mathrm{o}}}{R_{\mathrm{ct}}} \times 100
$$

where $R_{\text {ct }}^{\circ}$ and $R_{\mathrm{ct}}$ are the charge transfer resistances without and with inhibitor, respectively.

\section{Results and discussion}

\section{Morphology and contact angle measurement}

The 3D profilometer images and contact angle of a water droplet $(2 \mu \mathrm{L})$ on the naked MS surface and MMS surface are presented in Figure 2. In general, low contact angle represents the hydrophilic surface and high contact angle represents the hydrophobic surface [15-16]. In the present study, the contact angle of the naked MS is $77.15^{\circ}$ (Figure 2a) and that of LF covered MS is $92.9^{\circ}$ (Figure $2 \mathrm{~b}$ ). This indicate that the LF modified MS surface is more hydrophobic than the bare MS surface. Moreover, the noticeable change in contact angle value on MMS may be due to the formation of a well packed layer of LF molecules. The compact layer on MMS may be attributable to the adsorption of differently oriented LF molecules on different sites of MS surface, which affords a barrier effect against the diffusion of chloride ions [17]. On the other hand, the surface of polished MS is comparatively rough and the smooth surface of MMS may be due to the uniform coverage of LF molecules. Thus, the surface morphology and contact angle measurements substantiates the formation of LF film on the MS surface.
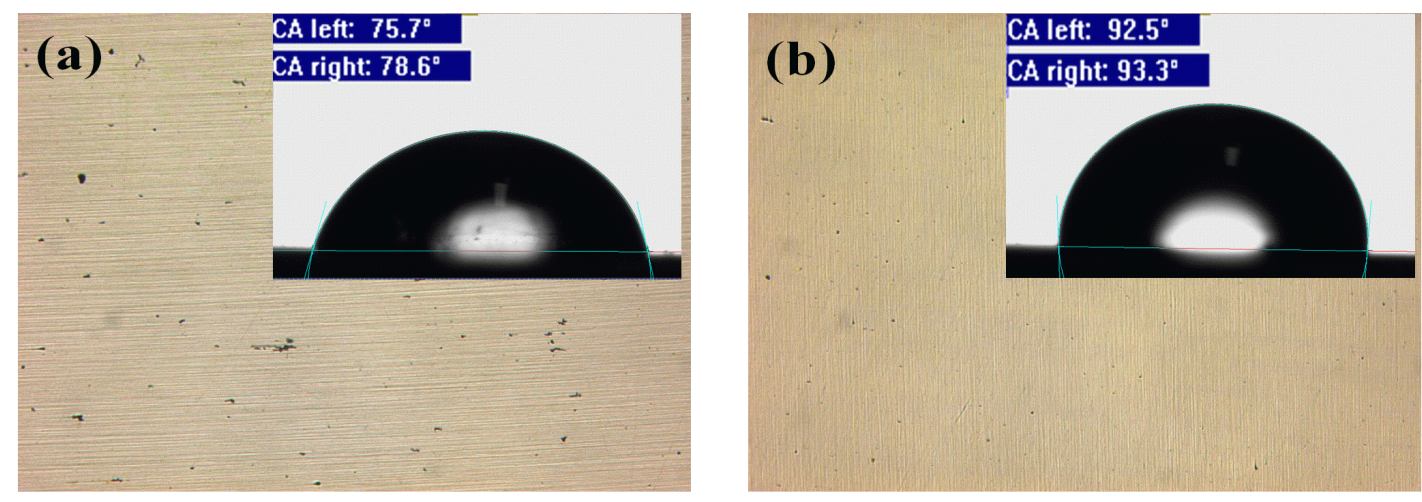

Figure 2.Profilometer images and optical micrographs of a water dropleton

(a) the naked mild steeland (b) modified mild steel.

\section{IR spectral analysis}

The IR spectra were used to determine the presence of LF film on the modified MS surface and are depicted in Figure 3.By comparing Figure $3 a$ and 3b, it can be observed that certain peaks have been disappeared completely and some have been shifted. Figure 3a shows the IR spectrum of LF molecule. The characteristic bandat $3490 \mathrm{~cm}^{-1}$ and $1459 \mathrm{~cm}^{-1}$ wereattributed to stretching vibration of the $\mathrm{O}$-Hand aromatic $\mathrm{C}=\mathrm{C}$ groups, $1151 \mathrm{~cm}^{-1}$ corresponds to $\mathrm{C}-\mathrm{N}$ bond, $2864 \mathrm{~cm}^{-1}$ corresponds to aromatic and $2953 \mathrm{~cm}^{-1}$ corresponds to aliphatic $\mathrm{C}-\mathrm{H}$ stretching. Also the band at $874 \mathrm{~cm}^{-1}$ is attributed to $\mathrm{C}-\mathrm{Cl}$ stretching. The IR spectrum of LF film on MMS is shown in Figure $3 b$. In this spectrum, C-N stretching frequency is shifted to $1122 \mathrm{~cm}^{-1}$, and aromatic $\mathrm{C}=\mathrm{C}$ stretching frequency is shifted to $1409 \mathrm{~cm}^{-1}$. Furthermore, the $\mathrm{O}-\mathrm{H}$ band at $3490 \mathrm{~cm}^{-1}$ gets disappeared in Figure $3 \mathrm{~b}$. Based on these observations, it can be concluded that the adsorption of LF molecule on MS surface takes place through $\mathrm{C}=\mathrm{C}, \mathrm{O}-\mathrm{H}$ and $\mathrm{C}-\mathrm{N}$ bonds and confirms the adsorption of $\mathrm{LF}$ molecules on the MS surface. 


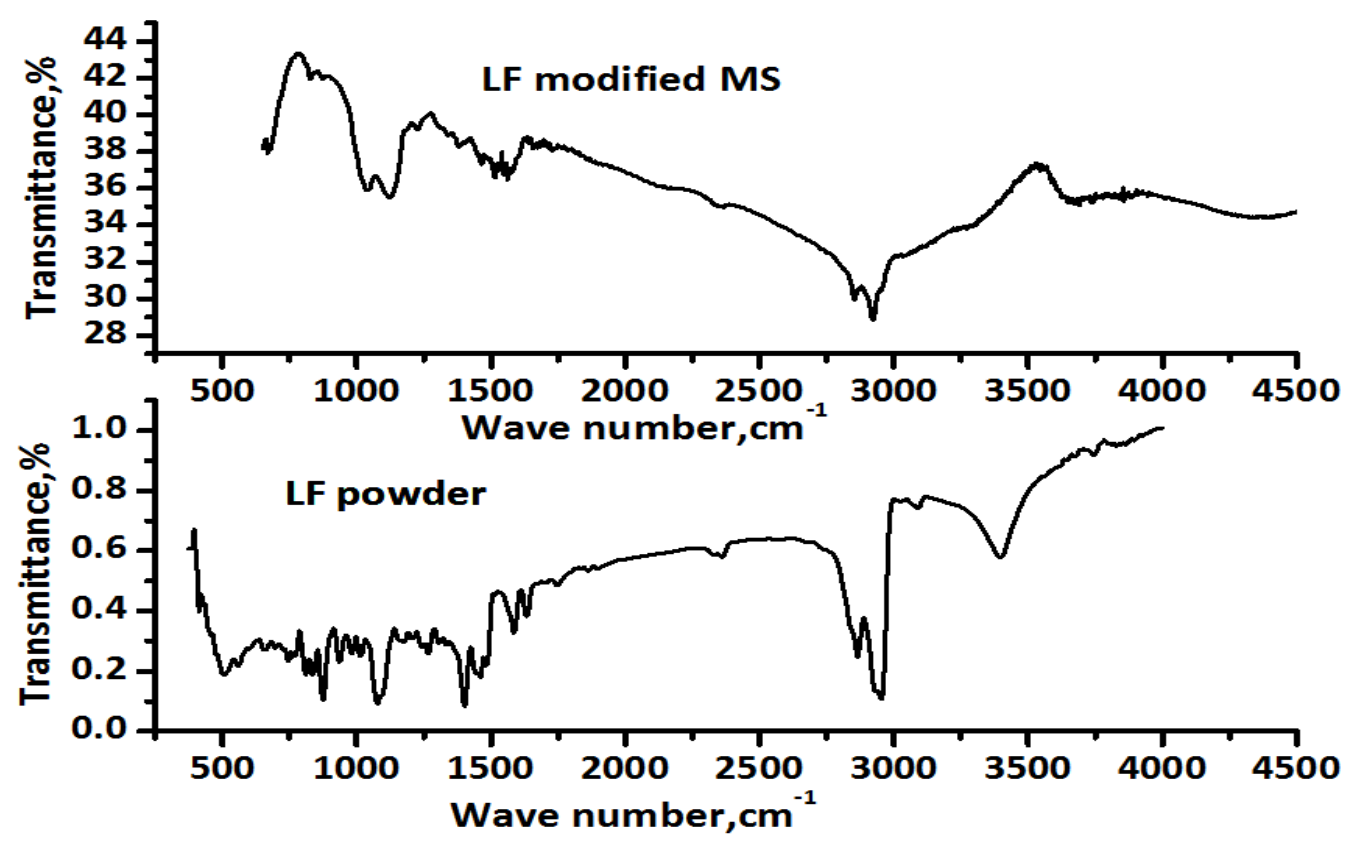

Figure 3. IR spectra of (a) LF powder and (b) LF film on the mild steel surface.

\section{Quantum chemical Study}

Quantum chemical calculations will provide information about the molecular structure of LF molecule responsible for the formation of film on the MS surface. The quantum chemical calculations were carried out with the help of complete geometry optimization by ab initio method using 6-31G** basis set. The geometry of LF molecule was optimized by Hartree-Fock method and the optimized structure, distribution of highest occupied molecular orbitals (HOMO) and lowest unoccupied molecular orbitals LUMO are shown in Figure 4. The calculated quantum chemical parameters are presented in Table 1.

Table1. Quantum chemical parameters of $L F$

\begin{tabular}{lc}
\hline \multicolumn{2}{c}{ Quantum chemical parameters } \\
\hline$E_{\mathrm{HOMO}} / \mathrm{eV}$ & -8.009 \\
$E_{\mathrm{LUMO}} / \mathrm{eV}$ & 1.525 \\
$\Delta E / \mathrm{eV}$ & 9.534 \\
$\mu / \mathrm{D}$ & 4.495 \\
Total energy, $\mathrm{k} \mathrm{cal} \mathrm{mol}^{-1}$ & -1670734.09 \\
\hline
\end{tabular}

The spatial orbitals are distributed randomly on $\mathrm{O}, \mathrm{N}$ and phenyl rings present in the molecule. Moreover, LF molecule possesshigh dipole moment $(\mu)$ and the low energy gap $(\Delta E)$ values which indicate that electron transfer from LF to the surface takes place during the process of adsorption. Conversely, the adsorption centers of organic molecules can be approximated by net atomic charges in the molecule. The net atomic charges of some atoms present in LF molecule are given in Table 2. The regions of highest electron density on organic molecule are the most plausible sites of adsorption $[18,19]$. Therefore, N, O and some $\mathrm{C}$ atoms are the active centers, which have the strongest ability to bond to the metal surface. Thus, oxygen atom, nitrogen atom and $\pi$ electrons in the phenyl ring are the main active sites of adsorption on MS surface. By reviewing these 
findings, it can be deduced that LF forms a compact film by the process of adsorption on the surface of MS. As a result, the above experimental findings of IR spectral analysis are in good agreement with the quantum chemical results.
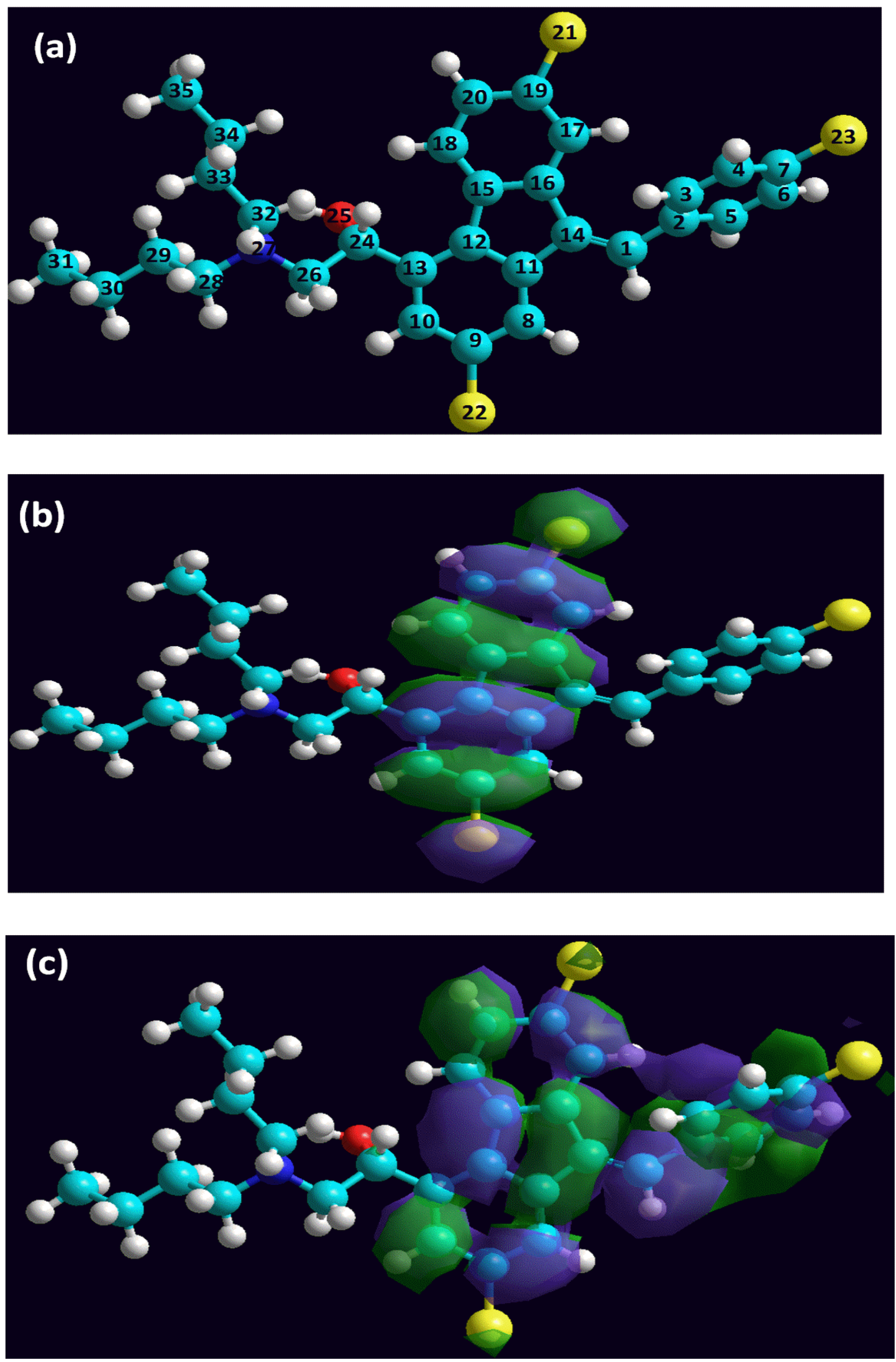

Figure 4.(a) Optimized structure, (b) distribution ofHOMOand (c) distribution of LUMO of LF molecule. 
Table 2.List of atoms having highest electron density in LF molecule.

\begin{tabular}{|c|c|}
\hline Atom & Charge \\
\hline$C(2)$ & -0.013 \\
\hline$C(3)$ & -0.026 \\
\hline$C(5)$ & -0.026 \\
\hline$C(18)$ & -0.025 \\
\hline $\mathrm{Cl}(21)$ & -0.116 \\
\hline $\mathrm{Cl}(22)$ & -0.116 \\
\hline $\mathrm{Cl}(23)$ & -0.116 \\
\hline $\mathrm{O}(25)$ & -0.386 \\
\hline$N(27)$ & -0.301 \\
\hline C (29) & -0.041 \\
\hline$C(30)$ & -0.055 \\
\hline$C(31)$ & -0.065 \\
\hline C (33) & -0.041 \\
\hline C (34) & -0.055 \\
\hline C (35) & -0.065 \\
\hline
\end{tabular}

\section{Potentiodynamicpolarisation measurements}

Electrochemical analyses were performed to investigate the kinetics of electrode processes as well as the surface characteristics of the electrochemical system. The potentiodynamic polarization curves in $1 \mathrm{M} \mathrm{HCl}$ for the naked $\mathrm{MS}$ and $\mathrm{MMS}$ in different concentrations of $\mathrm{LF}$ solutions are given in Figure 5 . The electrochemical corrosion parameters such as corrosion potential $\left(E_{\text {corr }}\right)$, corrosion current density $\left(I_{\text {corr }}\right)$, anodic tafel slope $\left(\beta_{\mathrm{a}}\right)$, cathodic tafel slope $\left(\beta_{\mathrm{c}}\right)$ and inhibition efficiency $\left(\eta_{\mathrm{T}} / \%\right)$ are tabulated in Table 3 .

It is apparent from Figure 5 that increasing the LF concentration reduces both the cathodic and anodic current densities and the $E_{\text {corr }}$ get slightly shifted towards the anodic direction. Moreover, the decrease in both the anodic and cathodic current densities enumerated that the LF film formed on the MMS surface suppressed both the anodic and cathodic reactions [20]. This phenomenon may be due to the adsorption of the LF molecules, which in turn decreased the attack of chloride ions on the MS surface.

Table 3. Polarization parameters in $1 \mathrm{M} \mathrm{HCl}$ for the bare mild steel and modified mild steel in different concentrations of LF solutions.

\begin{tabular}{cccccc}
\hline$c / \mathrm{mM}$ & $-E_{\text {corr }} / \mathrm{mV}$ & $-\beta_{\mathrm{c}} / \mathrm{mV} \mathrm{dec}^{-1}$ & $\beta_{\mathrm{a}} / \mathrm{mV} \mathrm{dec}^{-1}$ & $I_{\text {corr }} / \mu \mathrm{A} \mathrm{cm}$ & $\eta_{\mathrm{T}} / \%$ \\
\hline 0.00 & 449 & 106.46 & 84.38 & 257.5 & \\
0.50 & 376 & 157.28 & 64.71 & 43.67 & 83 \\
0.75 & 370 & 148.77 & 71.03 & 30.89 & 88 \\
1.00 & 373 & 142.07 & 63.38 & 17.41 & 93 \\
3.00 & 365 & 154.30 & 60.75 & 14.58 & 94 \\
5.00 & 364 & 143.97 & 56.27 & 19.15 & 92 \\
\hline
\end{tabular}




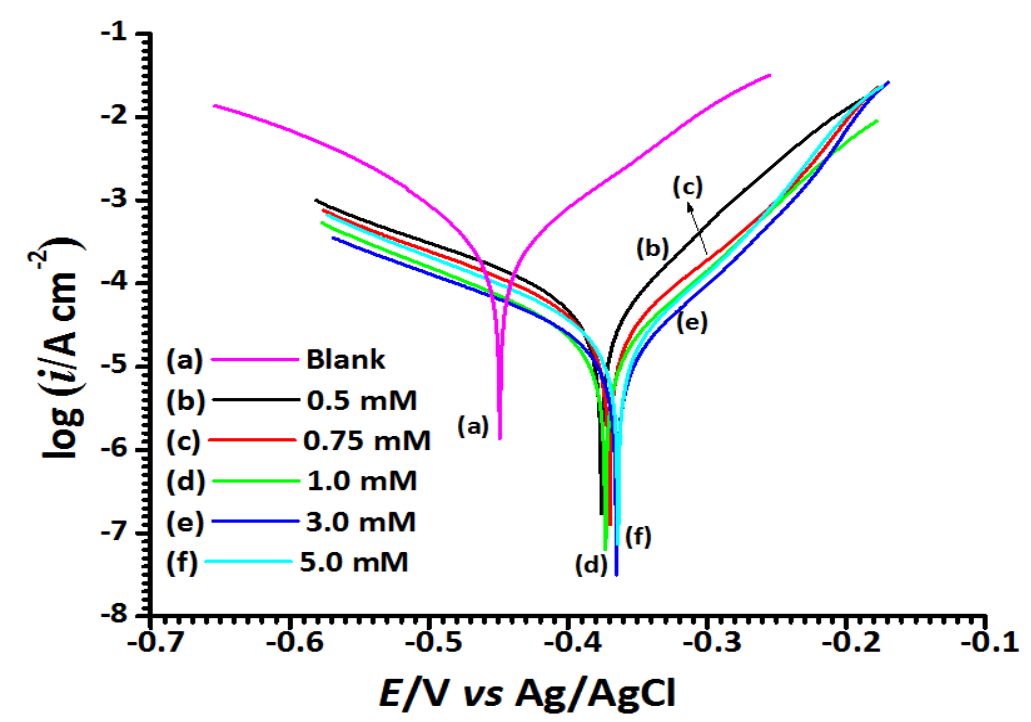

Figure 5. Potentiodynamic polarization curves in $1 \mathrm{M} \mathrm{HCl}$ for the naked mild steel and mild steel modified inpresence of different concentrations of LF.

It is apparent from the Table 3 that with increasing concentration of $L F, I_{\text {corr }}$ values lowered to its minimum value at $3 \mathrm{mM}$ and the $\eta_{\mathrm{T}}$ reached the maximum value $94 \%$. This implies that the film formed on the MS becomes denser with increase in LF concentration from 0.5 to $3 \mathrm{mM}$. But the $\eta_{\mathrm{T}}$ value decreases when the LF concentration is $5 \mathrm{mM}$. This may be due to the fact that the LF molecules get rearranged on the MS surface after the number of adsorbed molecules reaches a maximum value [21]. This makes easy for the acidic chloride ions to attack the MS surface through the interspaces. Furthermore, the values of $\beta_{\mathrm{a}}$ and $\beta_{\mathrm{c}}$ change with increase in inhibitor concentration and it indicates that the film inhibits both the anodic and cathodic reactions. By reviewing all these results it can be considered that the LF layer acts as a good protective film.

\section{Electrochemical Impedance spectroscopy measurements}

The Nyquist and Bode plots of the bare MS and LF covered MS in $1 \mathrm{M} \mathrm{HCl}$ are given in Figure 6 . For the naked MS, the impedance data were analyzed by the electrochemical equivalent circuit shown in the inset of Figure 6a. In this circuit, $R_{\mathrm{s}}$ represents the solution resistance, $R_{1}$ is the charge transfer resistance corresponding to the corrosion reaction at the MS/solution interface, and $C P E_{1}$ represents the constant phase element $(C P E)$ as a substitute for the double-layer capacitance $\left(C_{\mathrm{dl}}\right)$. The impedance of $C P E$ is defined as

$$
Z_{\mathrm{CPE}}=\mathrm{Q}^{-1}(j \omega)_{-\mathrm{n}}
$$

where $Q$ is the CPE constant, $\omega$ is the angular frequency, $j^{2}=-1$ is the imaginary number and $n$ is the CPE exponent which gives details about the degree of surface inhomogeneity resulting from surface roughness, inhibitor adsorption, porous layer formation etc.

For the bare MS, the Nyquist plot is the slightly depressed capacitive loop (Figure 6a) which indicates the roughness and other inhomogeneity of the MS surface [22]. The Nyquist and bode plots for MMS in different concentration of LF solutions were fitted by the equivalent circuit shown in Figure $7(\mathrm{a}) . R_{\mathrm{s}}, R_{1}$, and $C P E_{1}$ have the same meaning of elements in Figure 7a. In addition, $R_{2}$ represents the membrane resistance, which reflects the protective property of the film and $C P E_{2}$ is the capacitance of the film formed on MS [23-24]. The obtained impedance data are tabulated in Table 4. 

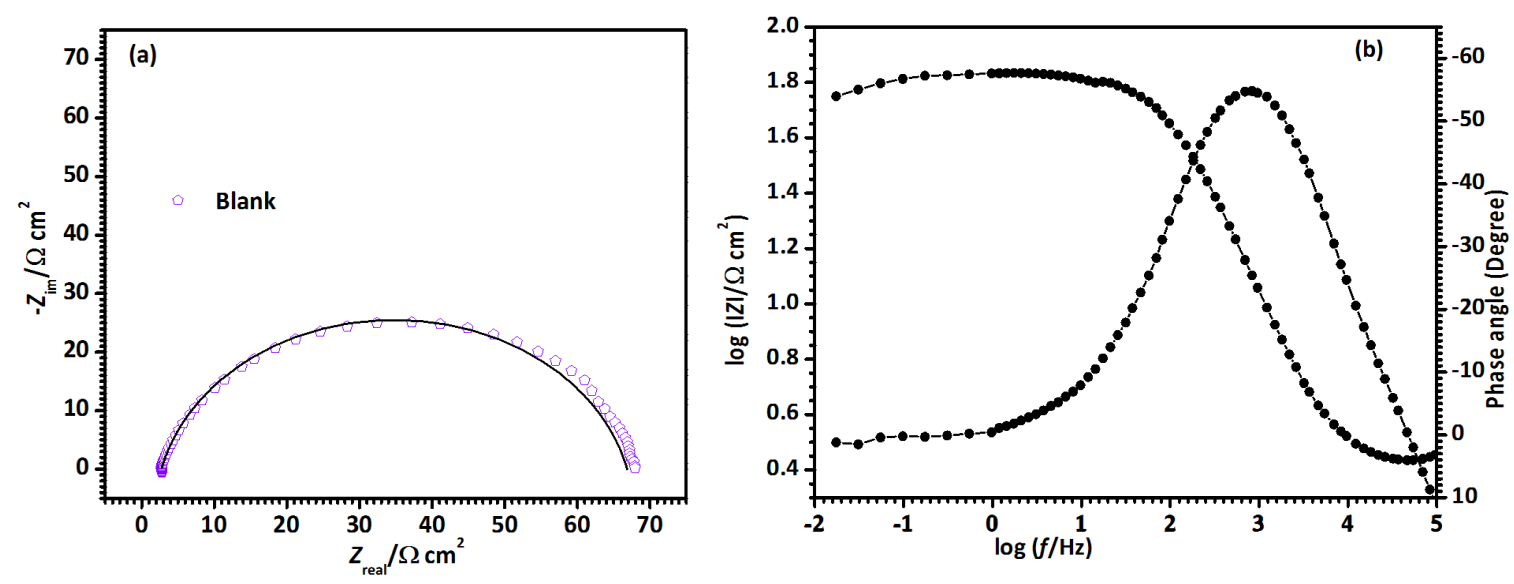

Figure 6. (a) Nyquist plot and (b) Bode plot of naked $\mathrm{MS}$ in $1 \mathrm{M} \mathrm{HCl}$
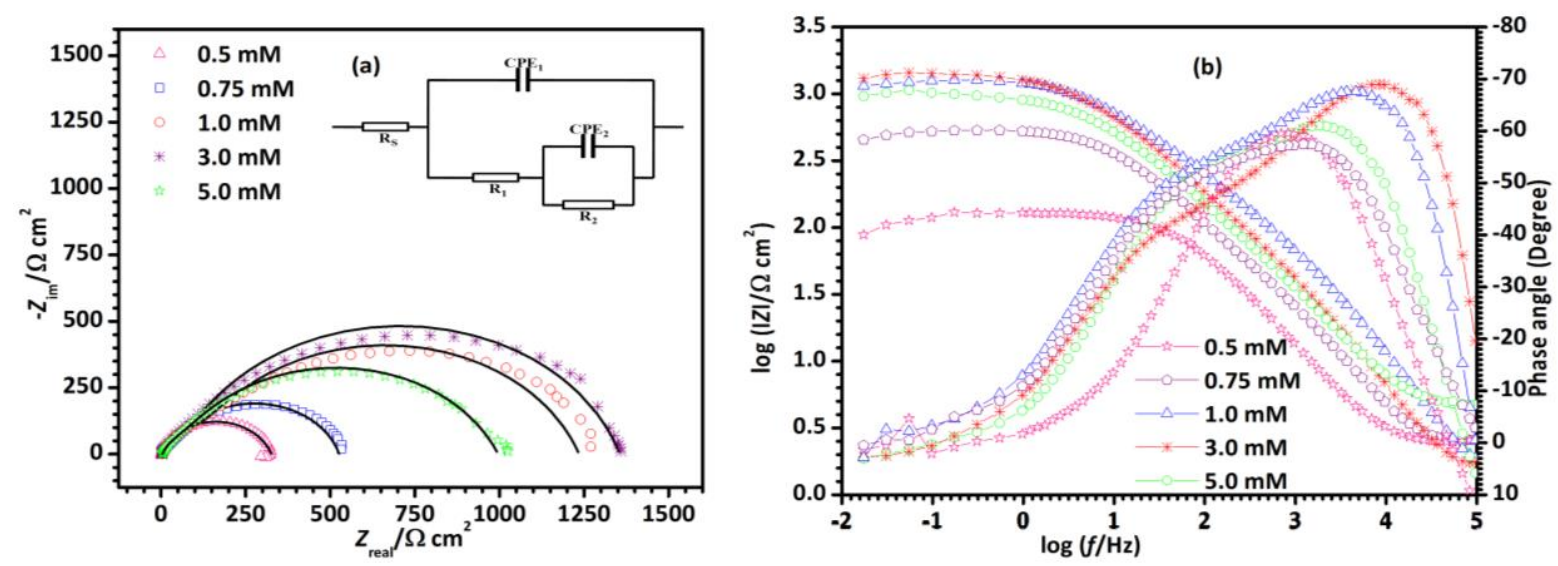

Figure 7. EIS results in $1 \mathrm{M} \mathrm{HCl}$ for LF covered mild steel modified in differentconcentration of LF solutions: (a) Nyquist plots; (b) Bode plots

Table 4.Impedance parameters in $1 \mathrm{M} \mathrm{HCl}$ for the naked mild steel and mild steel modified in presence of different concentrations of LF solutions.

\begin{tabular}{cccccccc}
\hline$c / \mathrm{mM}$ & $R_{1} / \Omega \mathrm{cm}^{2}$ & $Q_{1} / \mu \Omega^{-1} \mathrm{~S}^{\mathrm{n}} \mathrm{cm}^{-2}$ & $n_{1}$ & $R_{2} / \Omega \mathrm{cm}^{2}$ & $Q_{2} / \mu \Omega^{-1} \mathrm{~S}^{\mathrm{n}} \mathrm{cm}^{-2}$ & $n_{2}$ & $\eta_{2} / \%$ \\
\hline 0.00 & 64.14 & 56.26 & 0.856 & -- & -- & -- & \\
0.50 & 303.5 & 109.4 & 0.733 & 21.1 & 19.38 & 0.999 & 79 \\
0.75 & 499.3 & 51.68 & 0.829 & 24.95 & 17.16 & 0.954 & 87 \\
1.00 & 1136 & 34.93 & 0.730 & 98.02 & 64.51 & 0.921 & 94 \\
3.00 & 1292 & 37.84 & 0.815 & 61.75 & 11.20 & 0.946 & 95 \\
5.00 & 950.2 & 59.65 & 0.761 & 41.58 & 33.71 & 0.883 & 93 \\
\hline
\end{tabular}

It is apparent from Figure 7a that, the diameter of the capacitive loop increased to its maximum when the concentration of LF solution was $3 \mathrm{mM}$, implying that the compact film is formed on the surface of MS in this concentration. Bode plot shows two overlapped phase maxima, indicating the model of two time constants and the $Z$ modulus increases with the increase of LF concentration within $3 \mathrm{mM}$, suggesting that a dense film formed on the MS exhibit better protection efficiency. It is evident that the diameter of the capacitive loop and the logarithm of $Z$ modulus decreases when the concentration of LF is $5 \mathrm{mM}$. The inhibition efficiency calculated from $R_{1}$ also increases with increase in LF concentration, and reaches maximum ( $95 \%$ ) at $3 \mathrm{mM}$ concentration. This may be due to the hydrophobic film of LF molecules on MS surface which inhibited the dissolution 
reactions of $\mathrm{MS}$ to a greater extent in $1 \mathrm{M} \mathrm{HCl}$. The variation in $R_{1}$ values imply that the corrosion reaction on the MS surface was inhibited by the absorbed inhibitor film.

\section{Surface morphology}

Morphologies of metal samples were analysed by the true color images obtained from 3D profilometer. The true color images of bare $\mathrm{MS}$ and $\mathrm{MMS}$ immersed in $1 \mathrm{M} \mathrm{HCl}$ is shown in Figure 8. The surface of bare MS is completely damaged with large number of pits due to the attack of aggressive chloride ions. But MMS retains smoother surface owing to the presence of LF film which inhibits the process of corrosion in acidic chloride medium. Hence it can be concluded that, the film formed by the adsorption of LF molecules behaves as a barrier and retards MS corrosion in $\mathrm{HCl}$ media.
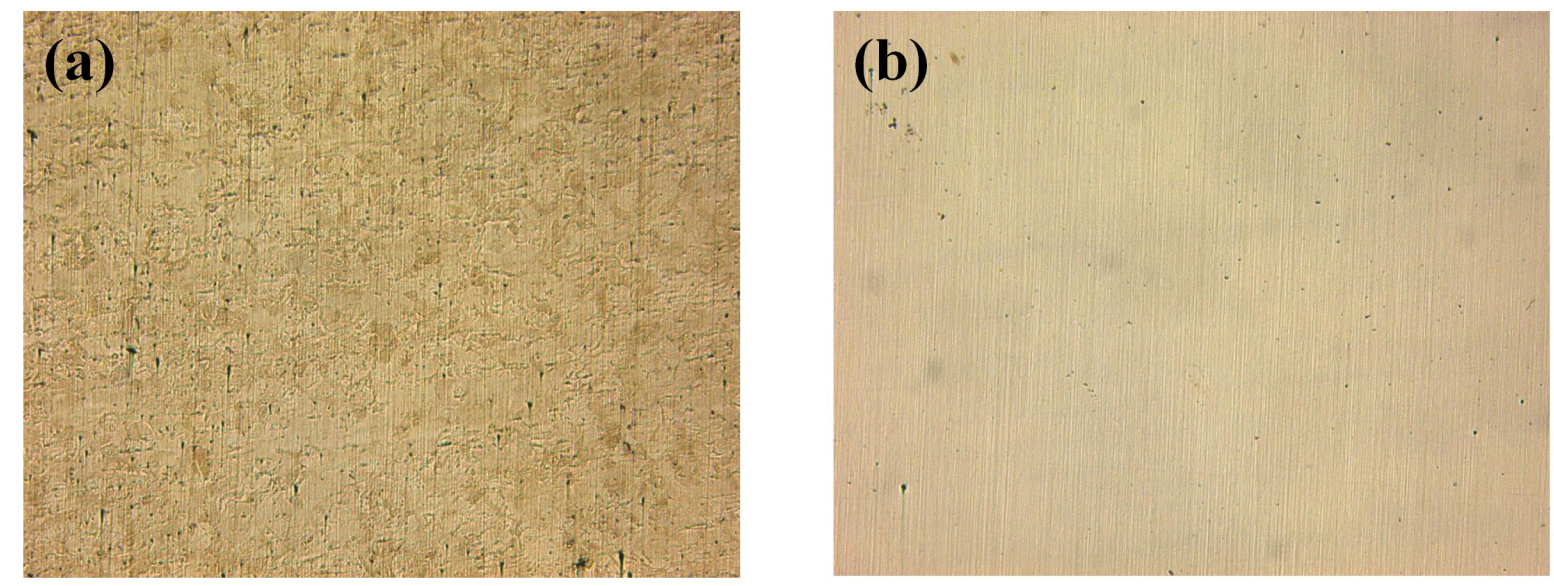

Figure 8. Profilometer images of (a) the naked mild steel and (b) modified mild steel after immersion in $1 \mathrm{M} \mathrm{HCl}$ for $1 \mathrm{~h}$.

\section{Conclusion}

The contact angle and IR analyses indicate the presence of LF molecules on mild steel surface. The quantum chemical study reveals that the $\mathrm{O}, \mathrm{N}$ and $\pi$ electrons in the LF molecule are the main active sites for adsorption. The chemical treatment of MS for about $1 \mathrm{~h}$ leads to the formation of compact film of LF molecules and hampers acid corrosion. The LF film inhibits anodic and cathodic reactions of $\mathrm{MS}$ in $1 \mathrm{M} \mathrm{HCl}$. The electrochemical studies and profilometer images confirmed the MS corrosion inhibition ability of LF molecules in acidic chloride solution.

Acknowledgement: The authors are grateful to the authorities of Department of Chemistry, Kuvempu University, Karnataka, India for providing lab facilities. Authors also thank Department of Science and Technology, New Delhi, Govt. of India [DST: Project Sanction No. 100/IFD/1924/20082009 dated 2.07.2008] for providing instrumental facilities. The authors are also gratified to University Grant Commission, New Delhi, Govt. of India [UGC grant Ref. 41-231/2012(SR) dated 16.07.2012] for providing HyperChem software facility.

\section{References}

[1] T.T.Qin, J. Li, H.Q. Luo, M. Li, N.B. Li, Corros. Sci.53 (2011) 1072-1078.

[2] Q.Q. Liao, Z.W. Yue, D. Yang, Z.H. Wang, Z.H. Li, H.H. Ge, Y.J. Li, Corros. Sci.53 (2011)19992005.

[3] D.Q. Zhang, L.X. Gao, G.D. Zhou, Corros. Sci.46(2004) 3031-3040.

[4] N. Bellakhal, M. Dachraoui, Mat. Chem. Phy.85(2004) 366-369. 
[5] M. Dudukcu,G. Avcl, Res. Chem.Intermed.41(2015)4861-4871.

[6] H. B. Ouici,M. Belkhouda, O. Benali, R. Salghi, L. Bammou, A. Zarrouk, B. Hammouti, Res. Chem.Intermed.41(2015) 4617-4634.

[7] M. K. Pavithra, T. V. Venkatesha, M. K. Punith Kumar,K. Manjunatha, Res. Chem.Intermed.41(2015) 7163-7177.

[8] A. Samide,B. Tutunaru, C. Negrilab,Chem. Biochem. Eng. Quart.3(2011) 299-308.

[9] G. Gece, Corros. Sci.53 (2011) 3873-3898.

[10] I. Naqvi, A. R. Saleemi, S. Naveed, Int. J. Electrochem. Sci.6(2011) $146-161$.

[11] I. Ahamad, R. Prasad, M.A. Quraishi, Corros. Sci.52(2010) 3033-3041.

[12] I. Ahamad, R. Prasad, M.A. Quraishi, J. Solid State Electrochem.14 (2010) 2095-2105 .

[13] U. M. Eduok,M. Khaled, Res. Chem.Intermed.41(2015) 6309-6324 .

[14] M. K. Pavithra, T. V. Venkatesha, M. K. Punith Kumar, N. S. Anantha, Res. Chem.Intermed. (2015)DOI 10.1007/s11164-015-2158-3 .

[15] S. Khorsand, K. Raeissi, F. Ashrafizadeh, Appl. Surf. Sci.305(2014) 498-505.

[16] N. Wang, D. Xiong, Appl. Surf. Sci.305(2014) 603-608.

[17] H. Dadafarin, E. Konkov, S. Omanovic, Int. J. Electrochem. Sci.8(2013)369-389.

[18] P. Wang, D. Zhang, R. Qiu, Y. Wana, J. Wua, Corros. Sci.80(2014) 366-373.

[19] M. K. Pavithra, T. V. Venkatesha, M. K. Punith Kumar, N. S. Anantha,J. Electrochem. Sci. Eng. 5(2) (2015) 115-127.

[20] Y-C.Pan , Y.Wena, X-Y. Guo, P.Song, S. Shen, Y-P. Dub, H-F. Yang,Corros. Sci.73(2013) 274280.

[21] W.J. Guo, S.H. Chen, H.Y. Ma, J. Serb. Chem. Soc.71 (2006)167-175.

[22] J. Zhang, X.L. Gong, H.H. Yu, M. Du, Corros. Sci.53 (2011) 3324-3330

[23] N. E. Hamdania, R. Fdila, M. Tourabi, C. Jama, F. Bentiss, Appl. Surf. Sci.357 (2015) 12941305 .

[24] M. Lebrini, F. Robert, C. Roos, Int. J. Electrochem. Sci.6(2011) 847-859.

(C) 2016 by the authors; licensee IAPC, Zagreb, Croatia. This article is an open-access article distributed under the terms and conditions of the Creative Commons Attribution license (http://creativecommons.org/licenses/by/4.0/) 